\title{
A paisagem no Plano Diretor Municipal: uma reflexáo sobre sua referência na legislaçáo urbanística dos municípios paranaenses
}

Fernando Caetano. Serviço Social Autônomo Paranacidade, Curitiba, Brasil. Alessandro Rosaneli. Universidade Federal do Paraná, Curitiba, Brasil.

RESUMO | A paisagem está na pauta das preocupaçôes contemporâneas em relação ao ordenamento do uso e ocupação do solo urbano e rural. O objetivo desse trabalho é identificar como o conceito de paisagem tem sido tratado como tema do planejamento urbano na legislação urbanística. Para tanto, são analisados 381 Planos Diretores de municípios do Estado do Paraná, no Brasil, utilizando-se do método de análise de conteúdo. Complementarmente, procura-se compreender quais ideias de paisagem aparecem em suas principais leis constituintes, observando as cinco problemáticas da paisagem definidas por Jean Marc Besse. Os resultados mostram que predominam certas ideias em detrimento de outras em função da reprodução de disposiçôes gerais dos instrumentos da política urbana, já previstas em legislação federal e pela aplicação de modelos-padrão de leis em municípios distintos.

PALAVRAS CHAVE | planejamento urbano, política urbana, teoria urbana.

ABSTRACT | Landscape is one of the matters on the agenda of contemporary concerns regarding urban and rural land use. The objective of this paper is to identify how the concept of landscape has been treated as a theme of urban planning in planning legislation. For this, 381 comprehensive plans of Paraná State municipalities, Brazil, are analyzed, using content analysis methods. The revision seeks to understand what ideas of landscape appear in the legal documents, taking in account the five classifications of complexities of landscape defined by Jean Marc Besse. The results show that certain ideas predominate over others due to the reproduction of general provisions of urban policy instruments already provided for federal legislation and the application of standard models of law in different municipalities.

KEYwORDs | urban planning, urban policy, urban theory.

Recevido em 7 de julho de 2017, aprovado em 9 de dezembro de 2017

E-mails: F. Caetano, caetano@paranacidade.org.br |A. Rosaneli, alessandrofilla@ufpr.br 


\section{Panorama inicial}

Descrever uma paisagem pode ser um ato simples e trivial, uma forma descompromissada de expressar as cenas do cotidiano; mas também pode ser uma ação carregada de emoçáo, quando se expressa sentimentos sobre algum lugar; ou algo racional e sistêmico, na ocasião em que se pretende enunciar as características dos ambientes naturais e construídos ao longo do tempo; e até mesmo a manifestação da imaginação, quando se idealiza a construção de um espaço onde se viverá. Observa-se, portanto, que esse termo pode ser empregado para externar uma infinidade de situaçóes e tentar abarcar simultaneamente todas as suas possibilidades não é tarefa fácil, se viável. Por outro lado, compreende-se que preterir, ou mesmo não reconhecer, uma ou outra propriedade do conceito, pode incorrer em perigosa simplificação.

De muitos autores que buscam mediar essa pluralidade interpretativa sobre a paisagem, o filósofo Jean-Marc Besse reconhece que, mesmo possuindo uma forte componente subjetiva na sua definição, fruto da construção humana do conceito, a objetividade do mundo material também é essencial para a concepção das ideias de paisagem (Besse, 2014). Assim, a saída proposta por esse autor frente a tal problemática é identificar quais seriam as "portas" de leitura para a mesma. Segundo sua interpretação, de maneira geral, existiriam cinco possibilidades de análise da paisagem: i) "representação cultural e social"; ii) "produção do território habitado"; iii) "meio ambiente material e vivo"; iv) "experiência sensorial"; e v) "projeto".

Cabe ressaltar que mesmo as leituras mais materialistas da paisagem trazem em seu bojo resquícios de valores ou mesmo memórias dos sujeitos que as conceberam (Schama, 1996). Portanto, o valor de uma paisagem pode ser estritamente individual, como uma lembrança da infância vivida numa rua qualquer, ou tornar-se coletivo, como a presença de um rio que marcou o surgimento de uma cidade. Seja de caráter individual ou coletivo, o ser humano pode atribuir valor a uma paisagem, que a torna tão ou mais importante que outros tipos de riquezas materiais como, por exemplo, a paisagem cultural da cidade do Rio de Janeiro, reconhecida pela Organização das Nações Unidas para a Educação, a Ciência e a Cultura (unesco) como patrimônio da humanidade.

Dentre as diversas formas utilizadas pelo ser humano para resguardar seus valores materiais e imateriais coletivos, que representariam, em tese, um modelo ideal de sociedade a ser alcançado, as leis e demais normas jurídicas constituemse em expressivo expediente garantidor. Mais do que nunca, no contexto de uma sociedade capitalista, o reconhecimento dos valores individuais e coletivos que as paisagens têm é fundamental para a conquista da qualidade de vida humana e a construção da identidade social do sujeito. Dessa forma, a paisagem, reconhecida como um valor intrínseco da natureza humana, tem sido objeto de tutela, por meio de normatização legal, visando o seu reconhecimento e ordenamento, em prol do bem comum. Nesse contexto, a sociedade brasileira tem confiado na legislaçáo urbanística, em especial o Plano Diretor Municipal (PDM), para o reconhecimento e valorização da paisagem local. 
A "aposta" da sociedade no PDM, para atingir este e outros objetivos da política urbana, está consagrada na Constituição Federal (CF) de 1988, especificamente no capítulo da "Política Urbana". O artigo 182 da CF define o PDM como o instrumento básico de efetivação da política de desenvolvimento urbano, sendo obrigatório para municípios com mais de 20 mil habitantes. A CF definiu que a propriedade urbana cumpre a sua função social se atender às exigências fundamentais de ordenação da cidade expressas no PDM.

Em 2013, os resultados publicados da "Pesquisa de Informaçóes Básicas Municipais - MUNIC”, feita pelo Instituto Brasileiro de Geografia e Estatística (IBGE), mostraram que, dos 5.570 municípios brasileiros, 2.785 haviam elaborado seus PDMs, o que corresponde a $50 \%$ do total. Nessa pesquisa de abrangência nacional, o Paraná se destacou como o estado da federação que apresentou o maior número absoluto de municípios com PDMs elaborados, perfazendo um total de 368 planos. Como o Estado do Paraná possui 399 municípios, a MUNIC 2013 mostrou que 92\% dos municípios paranaenses já possuíam PDM naquele ano.

Assim, considerando: i) a relevância da paisagem como um aspecto fundamental para a qualidade de vida humana; ii) os pressupostos legais, federais e estaduais, para a elaboração de um PDM; e iii) a posição de destaque do Paraná quanto ao número de municípios com PDMs elaborados, o objetivo desse trabalho é expor como a paisagem foi tratada na legislação urbanística dos municípios paranaenses, bem como identificar, por meio do método de análise de conteúdo, quais ideias de paisagem apareceram nesse conjunto legal, dentre as cinco categorias de leitura da paisagem definidas por Jean Marc Besse. Compreende-se que tal tarefa possui o potencial de agregar postura crítica para a tomada de decisão no campo de conhecimento do planejamento urbano e regional em outros contextos urbanos. Para tanto, após uma rápida incursão sobre as possibilidades de compreensão do conceito de paisagem e sua aplicação em experiências legais e normativas, expóe-se uma sucinta discussão sobre a pertinência do PDM enquanto fato legal. Na sequência, são apresentadas as opçóes metodológicas e os resultados encontrados no recorte territorial definido.

\section{As várias formas de expressar o que é paisagem}

O conceito de paisagem não é universal. Para sua compreensão é necessário reconhecer as configuraçóes culturais das sociedades que o utilizaram com a intenção de expressar algo, geralmente relacionado à percepção visual humana do ambiente à sua volta, sem excluir as demais contribuiçóes de outras dimensóes sensoriais no ato de percepção e expressão paisagística (Custódio, 2014).

Ademais, essa autora aponta que a "sociedade paisagística" surgiu no Oriente, especificamente na China, onde a beleza e a sua retratação possuem inclusive um caráter religioso e social. Barros e Pádua (2014) afirmam que, no ocidente, a paisagem aparece como um movimento cultural a partir do Renascimento, por volta do século XVI, período marcado pela ascensão da razão e a libertação das artes em relação às restriçóes da igreja católica. Nesse período, segundo os autores, as escolas de pintura, nos territórios das atuais Holanda e Itália, começaram a trabalhar 
a representação de temas da natureza, "recortando-os" espacialmente e "enquadrando-os", delimitando assim "a paisagem".

Sandeville (2005) observa que, "nas línguas latinas paisagem tem origem no latim pagus (marco ou baliza metida na terra, território rural delimitado por marcos, distrito, aldeia, povoaçáo) " (p. 4). O autor afirma que a origem da palavra pagus remete a um território delimitado, com sentido de distrito ou aldeia, ou seja, algo relacionado ao campo, ao rural, distante da noção moderna de paisagem.

Ao analisar a origem do termo nas línguas anglo-saxôes, Cosgrove (2002) afirma que "as raízes etimológicas da paisagem radicam nas conexóes substanciais entre um coletivo humano (denotado pelos sufixos schaft, ship, scape) e seus direitos públicos de usufruto sobre os recursos naturais de uma área delimitada (land), como está estabelecido no direito habitual" (p. 71). O autor buscou identificar as origens do termo inglês "landscape", que decorre do alemão "landschaft". Segundo o autor, o termo alemão relaciona a paisagem com os limites políticos e administrativos de uma determinada regiáo, já o inglês associa a ideia de paisagem com a ideia de cena ou cenário, diretamente relacionada com a percepção visual do homem.

Para Custódio (2014), a visão de paisagem do século Xvi, como pano de fundo para representar a cultura humana, passou por modificaçóes históricas até o século XIX, e as pessoas foram, aos poucos, deixando de fazer parte das cenas retratadas nos quadros "paisagísticos", passando a natureza a ocupar um papel central. Foi no Romantismo do século XIX que a contemplaçáo da natureza se converteu em prazer estético, como forma de compensar ou contrapor-se a uma época em que o avanço dos métodos científicos, empíricos e objetivos levaram a um desencanto do mundo.

Sandeville (2005) critica a redução do conceito de paisagem à sua mera visibilidade formal, que aproxima a sua compreensão conceitual à ideia de pitoresco, cena ou cenário, resvalando no decorativo, superficial e acessório, quase que como algo de pouca importância frente a outras problemáticas humanas. O autor reforça que a paisagem vai muito além do espaço observado, trata-se do espaço vivenciado e da sensibilidade das pessoas em relação ao seu entorno.

Esse resgate das origens etimológicas do termo paisagem aponta para uma primeira ideia, já delimitada por Cosgrove e Jackson (1987), de paisagem como uma sofisticada construção cultural, um modo particular de compor, estruturar e dar sentido ao mundo exterior, cujo propósito decorre do interesse do ser humano de apropriação material da Terra. Além deste, existiriam outros propósitos para a paisagem, decorrentes ou não de outras ideias que se possam ter sobre a mesma? Um específico trabalho de Jean Marc Besse, publicada originalmente em 2009, caracteriza-se como uma importante referência contemporânea para responder a essa questão.

Nessa obra, o autor ressalta que existe atualmente uma polissemia e uma mobilidade essenciais do conceito de paisagem, muito em funçáo da fragmentação da formação dos profissionais que a enfrentam como objeto de pesquisa e/ou intervenção, como antropólogos, arquitetos e urbanistas, paisagistas, ecologistas, geógrafos, psicólogos, sociólogos, etc., muito em razão de que cada um desses campos disciplinares possui referenciais teóricos e interesses de pesquisa diversos. $\mathrm{O}$ autor, então, descreve cinco "portas", problemáticas paisagísticas contemporâneas, 
que não necessariamente se superpóem entre si, mas podem estar articuladas umas às outras. Tal ordenação revela-se importante para esse trabalho na medida em que permite assentar uma série de entendimentos que estão em suspensão e, assim, vislumbrar caminhos para sua aplicação na prática do planejamento urbano. Portanto, ela será seguida para explorar possíveis matrizes teóricas.

Na primeira abertura, como "representação cultural e social", argumenta-se que a paisagem se caracteriza como um modo de pensar e de perceber o mundo. Nessa perspectiva, a paisagem não existe objetivamente, ela é na verdade resultado do que o ser humano pensa dela. O autor afirma que, sob essa ótica, a paisagem surge como resultado da construçáo de sujeitos individuais ou coletivos, que a utilizam como forma de apropriação cultural do mundo, ideia também presente em Collot (2012).

Schama (1996) afirma que, antes de poder ser um repouso para os sentidos, a paisagem é obra da mente, composta tanto de lembranças quanto de extratos de rochas. Cosgrove (1998) ressalta que, a paisagem, de fato, é uma maneira de ver, uma forma de compor e harmonizar o mundo exterior em uma cena, em uma unidade visual. Esse modo de contemplar, no entendimento de Andreotti (2012), foi inventado pelo ser humano para falar de si mesmo, por meio da imagem.

Tal significação da paisagem, segundo Besse (2014), pressupóe uma teoria intelectualista da percepção, em que a apreensão humana nunca é puramente ingênua, pelo contrário, é sempre precedida por um ato de interpretação. Nesse aspecto, também se pode se recorrer à ideia expressa em Palka (1995), ao afirmar que “...cheiros, sons e tato, como sensaçóes experienciadas pelo observador, contribuem - assim como a visão - para a construção mental e a 'caracterização' da paisagem” (p. 72).

A segunda porta de leitura da paisagem é o seu entendimento como um "território fabricado e habitado", no qual o valor paisagístico de um lugar não é considerado apenas do ponto de vista estético, ainda que também o seja, mas, além do que isso, constitui-se como uma soma das experimentaçôes, dos costumes, das práticas desenvolvidas por grupos humanos nesse lugar. Dessa forma, a paisagem é primeiramente uma realidade objetiva, material, produzida pelas pessoas. Constitui-se também como elemento cultural não porque ela é vista por uma determinada cultura, mas porque foi produzida pela mesma, sedimentada pelo acúmulo histórico de práticas, construçóes, valores, etc. Besse (2014) aponta que, em essência, as paisagens são produzidas náo para ser observadas e/ou contempladas, mas sim como fruto da inserção do homem no mundo, como resultado da sua luta por sobrevivência e a sua afirmação perante os outros.

Jackson (1984) afirma que não se deveria usar a palavra paisagem para descrever nosso mundo privado ou nosso microcosmo por uma simples razão, a paisagem é uma concreta e tridimensional realidade compartilhada, igual a uma composição feita ou modificada pelo homem para servir de infraestrutura ou pano de fundo para a nossa existência coletiva.

Esse modo de compreender a paisagem também assinala que a interpretação das formas paisagísticas permite apreender algo sobre as sociedades que as produziram, questão convergente em Lynch (1975) e M. Santos (2002). O resultado dessa produção humana são paisagens nem totalmente naturais, nem totalmente humanas, talvez natureza humanizada ou humanidade naturalizada. Aqui a 
dimensão estética da paisagem torna-se irrelevante e ganha destaque sua dimensão social e política, como a expressão da busca do ser humano por modelos ideais de sociedade e de civilização.

O terceiro arrazoado proposto por Besse (2014) indica a paisagem como um "meio ambiente material e vivo das sociedades humanas", numa abordagem de caráter realista da paisagem, excedendo suas significações subjetivas ou sociais. Nesse caso, a paisagem caracteriza-se como um conjunto complexo e articulado de objetos, um campo da realidade material mais amplo e profundo que as representaçôes que a acompanham. A paisagem, assim, constitui-se pelo meio ambiente cujas evoluçóes são mais ou menos afetadas pelas açóes e sentimentos humanos, pois ela existia antes do ser humano e continuará existindo sem ele, de uma forma ou de outra. Como sintetiza Ab’Sáber (2003), paisagem é uma "herança".

Bertrand (2004), dentro dessa chave de leitura, afirma que a paisagem é "o resultado da combinação dinâmica, portanto instável, de elementos físicos, biológicos e antrópicos que, reagindo dialeticamente uns sobre os outros, tornam-a um conjunto único e indissociável e, em perpétua evolução". Para o autor, a paisagem se divide em apenas três categorias: a residual (estável), em trânsito (com perda de substância) e em acumulação. Também dentro dessa corrente de pensamento paisagístico, existe a defesa de que a paisagem deve ser estudada considerando os ritmos temporais dos diversos geofatores que a compóe, pois, "somente a geografia deu um valor científico ao conceito de paisagem, transformando-o em eixo de toda uma teoria de investigação" (Troll, 1997, p. 2).

A quarta porta de leitura associa a paisagem a uma "experiência fenomenológica”, onde seria uma experiência sensível, uma abertura às qualidades sinestésicas do mundo. Sob esse espectro, Besse (2014) coloca que as paisagens não são apenas vistas, mas sim experimentadas com todos os sentidos, são ambientes, meios, atmosferas, antes de serem objetos contemplados, ou seja, a paisagem é antes de tudo, uma experiência vivenciada.

Fenomenologicamente, a paisagem corresponde à presença do corpo, que é afetado, tocado pelo mundo ao seu redor, cujas texturas e espacialidades produzem sensaçóes específicas correspondentes ao lugar experienciado. Para Dardel (2013), a paisagem se unifica em torno de uma tonalidade afetiva dominante, colocando em questão a totalidade o ser humano e os seus vínculos existenciais com a Terra, como lugar, base e meio de sua realização. Para esse autor, a sensibilidade paisagística pode ser afetiva ou estranha, numa pureza de relação que afeta a carne e o sangue.

O reconhecimento do corpo na experiência da paisagem coloca o sujeito para fora de si mesmo, sendo um fora sem objeto, ideia recorrente em Collot (2012). Nessa experiência paisagística, segundo Besse (2014), a razão se rende à experimentação, resgatando as dimensôes sensoriais até então oprimidas pelo intelecto, reconhecendo que as verdadeiras portas de leitura da paisagem são os sentidos do corpo. A arte, como a poesia, talvez sejam formas de expressão mais adequadas para falar sobre essa experiência de paisagem, "implodindo" as formas materiais e deixando apenas a matéria e a energia como essências resultantes. Nessa abordagem, a obra de Tuan (1980) e de Jacques (2008) revigoram a importância do corpo na paisagem. 
A quinta e última maneira de leitura proposta por Besse (2014) entende-a como "projeto", onde a paisagem, ou a problemática paisagística, decorre da reflexão sobre os espaços habitados, considerando as relações e a integração com o solo, o território e o meio natural. O autor observa que, projetar a paisagem significa tanto pô-la em imagem (projeção) quanto imaginar o que ela poderia ser (projetação). Seria testemunhar para modificar, descrever para inventar. Sob essa ótica, projetar uma paisagem seria criar algo que já está presente, porém não é visto, pois o projeto inventa um território ao representá-lo e descrevê-lo. Seria a forma do ser humano colocar a sua inteligência a favor do movimento do mundo, para destacar nele certos elementos, reatando suas ligaçóes como se estivesse participando da sua criaçáo.

Essa ideia também aparece em Simmel (1913/2013) ao condicionar o nascimento da paisagem à necessidade que haja pulsação da vida, percepçáo e sentimento e que seja "arrancada" da natureza. Esse novo produto criado e/ou projetado passa à vida universal, acolhendo em seus limites o ilimitado. Essa compreensão pode ser identificada em McHarg (1969) e Forman (1996), que propóem alinhar as propostas de intervenção humana na paisagem com o entendimento do funcionamento da natureza.

Diante de tal conjunto de contribuiçóes, imaginam-se quais seriam as razóes de uma leitura imediata, até mesmo simplista, da paisagem no campo do planejamento urbano. De certa forma, a articulação ou superposição desses entendimentos não se constitui tarefa corriqueira e um panorama sobre alguns esforços pode exemplificar essa dificuldade.

\section{A referência à paisagem em atos normativos e orientativos}

A compreensão da complexidade dos distintos domínios da Terra tem se transformado com o tempo, mas se pode afirmar que é fato recente na história ocidental. Segundo Custódio (2014), a paisagem tem sido tema do direito desde fins do século XIX, quando o viés de tratamento da mesma em atos normativos, visando basicamente à sua proteção, a encarava como "um conjunto de patrimônios imóveis e estagnados" (p. 157).

Ao longo do século xx, com a ampliação dos significados do conceito de paisagem, a sua presença em atos normativos e orientativos também se desenvolveu para além da temática de patrimônio, ocupando espaço em atos de caráter ambiental, turístico, urbanístico, utilidade pública, etc. Custódio (2014) aponta que esse crescimento da presença da paisagem em atos de caráter normativo está relacionada com a "mudança de sua posição" (p. 157), de objeto a ser observado para objeto a ser vivido, representante da identidade cultural das comunidades.

Até 1992, a ideia de paisagem que se tinha nas conferências realizadas pela UNESCO era como ambiência ou algo ao redor que influi na percepção do bem protegido (Ribeiro, 2007). O autor afirma que, a partir desse ano, a unESCO passa a adotar a própria paisagem como um bem, com a valorização de todas as relaçóes que ali coexistem, representando uma ruptura com os entendimentos anteriores sobre a paisagem na instituição. 
Adicionalmente à Convenção do Patrimônio Cultural da unEsco (1972), e outros atos internacionais de proteção do patrimônio cultural, produzidos por esta instituição, foi elaborada em 2000, pelo Conselho da Europa, a Convenção Europeia da Paisagem (CEP). Segundo Ribeiro (2007), a CEP apresenta aspectos distintos da convenção da UNESCO, começando pelas diferenças de escala, a primeira com objetivo regional e a outra mundial. Além disso, o autor aponta que a diferença fundamental entre ambas é que a CEP atinge a todas as paisagens e náo apenas aquelas entendidas como bens patrimoniais. Diante disso, a CEP não se limita a inventariar os bens de valor excepcional, mas sim criar regras de proteção, gerenciamento e planejamento de todas as paisagens, constituindo-se num elemento fundamental de gestão do território.

A tal visão sistêmica da paisagem feita pela CEP, o mesmo autor associa a um contexto de unificação da Europa, que buscou estabelecer políticas públicas comuns. Mesmo assim, essa estratégia europeia é decorrente de um entendimento de que as paisagens sempre desempenharam um papel importante na construção das identidades nacionais e que, a partir da CEP, seria possível construir, de forma unificada, uma ideia de Europa por meio da representação de suas paisagens. Ou seja, a ideia de representaçáo cultural da Europa, por meio da paisagem, também estaria no cerne da CEP.

No Brasil, a CF de 1988 foi a primeira constituição brasileira a incluir no seu bojo a proteção ao meio ambiente (Custódio, 2014). A autora reporta essa inspiração constitucional aos princípios estabelecidos na Conferência de Estocolmo, em 1972, cujo objetivo era garantir a proteçáo do meio ambiente para as presentes e futuras geraçóes. A autora entende que ao falar de meio ambiente de forma ampla e irrestrita, a CF está também falando de paisagem.

Em relação ao tratamento da paisagem no corpo legal federal, Custódio (2014) fez extensa pesquisa de legislação, em distintas temáticas, visando identificar leis que de alguma forma apresentassem uma preocupaçáo, direta ou indireta, com a paisagem. No Estatuto da Cidade, lei que exerce influência determinante no conteúdo dos PDMs, o radical "paisag" aparece cinco vezes. A primeira ocorrência é no inciso XII do artigo $2^{\circ}$, que estabelece que a política urbana atinja seu objetivo mediante, dentre outros, do atendimento da seguinte diretriz: "proteção, preservação e recuperação do meio ambiente natural e construído, do patrimônio cultural, histórico, artístico, paisagístico e arqueológico".

$\mathrm{Na}$ sequência, o radical "paisag" aparece em três instrumentos da política de desenvolvimento urbano: Direito de Preempção, Transferência do Direito de Construir (TDC) e Estudo Prévio de Impacto de Vizinhança (EIV). No primeiro deles, o EC estabelece que o mesmo pode ser exercido pelo Poder Público quando destinar, dentre outros, à "proteção de áreas de interesse histórico, cultural ou paisagístico".

No segundo, para o proprietário cujo imóvel seja considerado de interesse paisagístico o EC faculta ao mesmo, por meio da TDC, exercer eventual direito adquirido de construir em outro imóvel, visando a preservação das características do imóvel anterior. Quanto ao terceiro instrumento, o EC estabelece que a paisagem urbana e o patrimônio natural e cultural são critérios, dentre outros, para avaliar os efeitos 
positivos e negativos de um determinado empreendimento ou atividade, quanto à qualidade de vida da populaçáo residente na área de sua implantação e proximidades.

A quinta ocorrência do radical "paisag" no EC se dá no artigo 54, alterando a redação do artigo $4^{\circ}$ da Lei $n^{\circ} 7.347 / 1985$, que disciplina a ação civil pública de responsabilidade por danos causados ao meio-ambiente, ao consumidor, a bens e direitos de valor artístico, estético, histórico, turístico e paisagístico. Apesar do EC apresentar uma certa preocupação com o patrimônio, o interesse ou o valor paisagístico, a simples inserção desses termos em lei, sem a sua necessária conceituação, dificulta ou mesmo impede a compreensão, por parte da sociedade, das reais intençôes do legislador e, consequentemente, o devido cumprimento do texto legal pelas autoridades competentes. Com essa sucinta recuperaçáo legal, pode-se afirmar que a paisagem é tema cada vez mais recorrente do corpo legal, em diversos níveis administrativos. Mas como será sua aplicação na dimensão mais afeita à vida cotidiana? A análise do nível municipal torna-se importante para perceber essa impregnação.

\section{Pequena reflexáo crítica sobre o Plano Diretor Municipal}

O senso comum que se tem sobre os PDMs no Brasil, institucionalizado por legislaçóes federais, estaduais e municipais, é de que ter um PDM é uma condição "imprescindível” para se alcançar o "desenvolvimento" urbano. O EC, por exemplo, estabelece que o Plano Diretor é o instrumento básico da política de desenvolvimento e expansáo urbana (artigo 40). Já em seu artigo 39, o EC estabelece que a propriedade urbana cumpra a sua função social se respeitar o que está definido no PDM, assegurando o atendimento às necessidades dos cidadáos quanto à qualidade de vida, à justiça social e ao desenvolvimento das atividades econômicas.

A preocupação com a dimensão política no desenvolvimento urbano também está presente em Harvey (2002). Para o autor, a busca de justiça social é um meio importante para obter melhor desempenho econômico e que os pensamentos e valores comunitários têm um papel potencialmente criativo. A coesão social como um esforço constante de desenvolvimento é, para Veiga (2006), ao mesmo tempo uma aposta e uma alavanca. Para o autor, no processo de desenvolvimento é necessário combinar: concorrência com cooperação; conflito com participação; e conhecimento local e prático com o científico.

Veiga (2005) ressalta que “(...) o objetivo básico do desenvolvimento é alargar as liberdades humanas. O processo de desenvolvimento pode expandir as capacidades humanas, expandindo as escolhas que as pessoas têm para viver vidas plenas e criativas" (p. 7). Para o autor, o âmago da questão do desenvolvimento está em definir formas de preservar e expandir as liberdades substantivas que as geraçóes atuais desfrutam sem comprometer a capacidade das geraçóes futuras de usufruir de liberdades semelhantes ou maiores.

A partir dessa reflexão, a qual o PDM está diretamente associado, pode-se afirmar que esse instrumento tem sido eficaz e efetivo em prol de um desenvolvimento urbano mais sustentável? Flávio Villaça tem sido um dos principais críticos no contexto brasileiro em relação à "pseudo-eficácia" do PDM como instrumento de planejamento urbano (Villaça, 1999a; Villaça, 1999b; Villaça, 2005). 
Conforme Villaça (1999a) o conceito de PDM se desenvolveu a partir da década de 50 e se caracterizou por um conjunto de diagnósticos técnico-científicos da realidade física, social, econômica, política e administrativa da cidade, resultando num conjunto de propostas de curto, médio e longo prazo para o futuro desenvolvimento socioeconômico e futura organização espacial dos usos do solo urbano, aprovados por lei municipal. Para o autor, a abrangência dos assuntos que o PDM pretensamente busca tratar, onde tudo que for importante para o município deve constar no mesmo, contribui para a sua inoperância e descrédito.

$\mathrm{O}$ autor afirma que a ilusão exposta nos PDMs e Planos Regionais decorre do abismo que separa o seu discurso das práticas das administraçóes municipais e da desigualdade que caracteriza a realidade política e econômica brasileira. $\mathrm{O}$ autor defende que o planejamento urbano no Brasil, representado pelo PDM, demanda uma revisão radical, passando pelo questionamento de todos os seus pressupostos, principalmente aqueles relacionados com o seu conteúdo e método. $\mathrm{O}$ estudo feito por Pereira (2010) sobre a situação dos PDMs no Paraná reforça a tese de Villaça dos PDMs carregados de discurso sem auto aplicabilidade.

Da mesma forma, o desafio de trabalhar com o conceito de paisagem num PDM também demanda uma revisão dos processos tradicionais usualmente adotados para a elaboração/revisão do mesmo. Como exemplo, Cancela d'Abreu, Botelho, Oliveira e Afonso (2011) promovem leitura funcional, sistêmica e objetiva da paisagem para orientar na implementação da CEP na revisão dos PDMs, principalmente no território português. Assim como Santos (2003), os autores propóem que a paisagem seja assumida com o mesmo nível de importância de qualquer outra componente essencial da elaboração de um PDM.

De certa forma, a necessidade do planejamento da paisagem refletir o que as pessoas pensam e sentem sobre a mesma já havia sido apontada por Dearden (1984). Em seu estudo, o autor demonstrou empiricamente haver correlação positiva entre as preferências de paisagem demonstradas pelo sujeito com aquelas com as quais o mesmo tenha convivido ou experienciado ao longo de sua história de vida. Nesse sentido, talvez as ideias de paisagem contidas nos PDMs representem em igual ou maior proporçáo as preferências paisagísticas de quem os elaborou, como consultorias técnicas contratadas, do que, necessariamente, as preferências de paisagem dos diversos grupos de indivíduos habitantes do local.

\section{Opções metodológicas para identificação das ideias de paisagem nos PDMs}

Para possibilitar a identificação das ideias de paisagem nos PDMs do Paraná foi utilizado como método de pesquisa a "Análise de Conteúdo", do tipo categorial, proposta por Bardin (2002). Essa análise funciona por meio do desmembramento do texto em unidades de análise, reagrupando-as segundo algum critério analógico. As unidades de análise se subdividem em "unidades de registro", "unidades de contexto" e "unidades de significado".

A unidade de registro é o tópico de significação a codificar e corresponde à parte do conteúdo do texto considerada como unidade base, visando à categorização e a contagem frequencial. Nessa pesquisa, a unidade base de registro foi o radical 
"paisag". Adicionalmente, foram consideradas outras unidades de registro, de caráter secundário, que também podem transmitir ideias de paisagem nelas contidas, como: ambiência, ambiente, cênic $(\mathrm{o} / \mathrm{a})$, cenário, entorno, panorâmic $(\mathrm{o} / \mathrm{a})$, patrimônio e vizinhança.

Além das unidades de registro, Bardin (2002) reporta como importante o levantamento das unidades de contexto. Segundo a autora, a unidade de contexto serve de unidade de compreensão para classificar a unidade de registro. Nessa pesquisa, as unidades de contexto se caracterizaram por palavras ou expressóes diretamente vinculadas ao radical "paisag" encontrado no PDM.

A partir do levantamento das unidades de registro, com as unidades de contexto a elas associadas, foi feito um exercício de identificação e classificação dos significados (ideias) por trás de cada uma das unidades de registro coletadas. Para categorização dos significados do radical "paisag" foram utilizadas as cinco portas de leitura da paisagem propostas por Besse (2014). Quando não foi possível categorizar a unidade de registro encontrada, a ela foi atribuída a categoria de "indefinido".

Dentre todo o conjunto de documentos que compóem um PDM foi analisada a ocorrência da paisagem apenas na própria Lei do PDM e na Lei de Uso e Ocupação do Solo (LUOs) mais conhecida como zoneamento. A opção por analisar as referidas leis decorre do entendimento, em tese, de que as mesmas representam a proposição de ideias para o desenvolvimento urbano (Lei do PDM) e, por outro, a materialização dessas ideias em norma de ordenamento e controle do crescimento urbano (LUOS).

Dos 399 municípios do Paraná, 95\% deles possuíam PDMs vigentes em 2017, ano da coleta de dados, o que correspondeu a 381 observaçóes de Lei de PDM e Luos.

\section{Aplicação da análise de conteúdo no objeto de pesquisa}

Dentre os 381 pDMs do Paraná pesquisados, o radical "paisag” ocorre ao menos uma vez nas leis de PDM de 369 municípios, ou seja, em 96\% do material analisado. Já nas LuOs, o mesmo radical aparece no mínimo uma vez em 267 municípios, ou 70\%. Em números absolutos, o levantamento realizado totalizou 3.391 ocorrências do radical "paisag" nas Leis de PDM, representando uma média de 9 ocorrências por município. Nas Luos, foram totalizadas 998 ocorrências do radical "paisag", correspondendo à média de aproximadamente quatro ocorrências por município. Esses números iniciais mostraram que o radical "paisag" apareceu 2,25 vezes mais nas Leis de PDM do que nas Luos.

O município que apresentou maior número de ocorrências foi Telêmaco Borba (58), seguido de Pato Branco (43) e Guarapuava (33). Arrisca-se a dizer que, de maneira geral, as paisagens destes municípios não apresentam algo singular os diferencie dos demais municípios do interior do Paraná. Ainda assim, esses municípios apresentaram números de ocorrências superiores ao de Curitiba (26), capital do Paraná, referência internacional em planejamento urbano. Para se ter uma ideia, nas Leis de PDM das duas maiores cidades brasileiras, São Paulo e Rio Janeiro, o radical "paisag" aparece 104 e 91 vezes, respectivamente, apontando que, no Paraná, o radical "paisag" pouco aparece nas Leis de PDM. 
Na Lei do PDM de Telêmaco Borba, as ocorrências do radical "paisag" que mais se repetiram foram: "proposta temática de paisagismo" com sete ocorrências e "patrimônio paisagístico" com cinco ocorrências. Percebe-se na Lei de PDM deste município uma preocupação em se utilizar do "projeto" da paisagem como estratégia para fomentar o desenvolvimento econômico local, por meio do turismo. Em Pato Branco, se destacaram numericamente as seguintes ocorrências: "zona especial de interesse paisagístico e ambiental" com sete ocorrências e "valor paisagístico" com três ocorrências. Em termos qualitativos, há que se destacar na Lei do PDM de Pato Branco as preocupaçóes com: i) a garantia do direito de usufruir a paisagem; ii) a não hierarquização da paisagem construída sobre a natural; e iii) a participação do cidadão na identificação, leitura e compreensão da paisagem.

Nas Luos do Paraná, as maiores ocorrências do radical "paisag" foram nos municípios de Paranaguá (37) e Pato Branco (24). Na Luos de Paranaguá destaca-se numericamente as ocorrências "qualificação da paisagem" (6) e "respeito às características paisagísticas” (4). Em Pato Branco a Luos dá destaque, assim como foi dado em sua Lei de PDM, à ocorrência "zona especial de interesse paisagístico e ambiental" com oito ocorrências.

Ao se analisar os resultados do levantamento das unidades de registro secundárias percebem-se que, tanto nas Leis de PDM e Luos do Paraná, duas situaçóes: uma primeira, em que as ocorrências das palavras "ambiência", "beleza cênica", "cenário" e "panorâmic(o)(a)" apresentaram, em geral, resultados numéricos muito baixos ou nulos, quando comparados com os resultados obtidos para o radical "paisag". Sendo assim, a adiçáo dos resultados das ocorrências destas unidades de registro secundárias à unidade registro principal quase que não alterariam o resultado final das ocorrências, considerando apenas o radical "paisag".

Já as ocorrências das outras unidades de registro secundárias levantadas (ambiente, entorno, patrimônio e vizinhança) apresentaram resultados expressivos, quando comparados com os resultados obtidos para o radical "paisag". A palavra ambiente apresentou, em geral, número de ocorrências superior, em maior ou menor proporção, das ocorrências de "paisag". No caso das ocorrências de "entorno", "patrimônio" e "vizinhança” os resultados obtidos estão mais próximos aos do radical "paisag", ora um pouco superiores, ora um pouco inferiores.

Porém, há que se observar que, em relação às ocorrências das palavras "ambiente", "entorno", "patrimônio" e "vizinhança" nas Leis de PDM e LuOs, nem todas essas ocorrências estão diretamente relacionadas a ideias de paisagem, como nos seguintes exemplos encontrados: "recursos do fundo para o meio ambiente", "entorno urbanizado e com infraestrutura básica implantada", "imóveis integrantes dos bens dominiais do patrimônio público" e "Estudo Prévio de Impacto de Vizinhança". Para que se pudesse tirar conclusóes mais precisas sobre os resultados das ocorrências das unidades de registro secundárias seria necessário selecionar previamente apenas aquelas que apresentassem ideias de paisagem. Como este trabalho preliminar náo foi realizado, seus resultados foram desconsiderados nesta pesquisa. 


\section{Análise das unidades de contexto}

Nas Leis de PDM, as cinco maiores ocorrências do radical "paisag” foram: i) "patrimônio paisagístico" (420); ii) "proteção de áreas de interesse paisagístico" (257); iii) "paisagem urbana” como questão a ser considerada no Estudo Prévio de Impacto de Vizinhança (136); iv) "área de interesse paisagístico" (112); e v) "imóvel de interesse paisagístico" (107).

Pode-se afirmar que estes resultados mais expressivos são fruto da reprodução, nas Leis de PDM, das disposiçóes da CF e do EC sobre o patrimônio paisagístico, e do EC sobre os seguintes instrumentos da política de desenvolvimento urbano: i) Direito de Preempção; ii) Transferência do Direito de Construir; e iii) Estudo Prévio de Impacto de Vizinhança (EIV).

Nas Luos, as cinco maiores ocorrências do radical "paisag", associadas às suas unidades de contexto, foram: i) "patrimônio paisagístico" (62); ii) "valor estético e paisagístico natural ou cultural", (53); iii) "função ambiental de preservar a paisagem" (49); iv) "tratamento paisagístico" (49); e iv) "valor paisagístico" (49). No caso das Luos, à exceção da ocorrência "patrimônio paisagísitico", as maiores ocorrências do radical "paisag" estão relacionadas à reprodução de modelos padrão de legislação urbanística de uso e ocupação do solo no processo de elaboração do PDM. De fato, os PDMs do Paraná foram elaborados, com poucas exceçóes, com a contratação de empresas de consultoria especializada. De maneira geral, a estratégia comercial dessas empresas para atender ao mercado de elaboração de PDMs é oferecer modelos-padrão de legislação urbanística, "adaptáveis" a qualquer realidade municipal, com maior ou menor grau de customização, em função de eventuais demandas locais.

Para ilustrar a influência da reprodução de modelos-padrão de legislação urbanística de PDMs pelo Paraná nos resultados das ocorrências do radical "paisag”, em suas Leis de PDM e LuOs, foram selecionados os municípios que se encontram na faixa média de ocorrência do radical "paisag” nas Leis de PDM, com nove ocorrências (tabela 1).

Os 35 municípios que apresentaram nove ocorrências foram divididos em oito grupos distintos. Destes oito grupos, cinco deles apresentaram resultados idênticos das unidades de registro e de contexto levantadas. No primeiro grupo, com onze municípios com resultados idênticos, identificou-se que sete destes tiveram seus PDMs elaborados por uma mesma consultoria, enquanto os outros quatro municípios tiveram seus PDMs elaborados por quatro consultorias diferentes.

O segundo, terceiro e quinto grupos, com municípios com ocorrências idênticas do radical "paisag", reúnem também PDMs elaborados por uma mesma consultoria. Já os municípios do quarto grupo possuem ocorrências idênticas do radical "paisag”, porém tiveram seus PDMs elaborados por consultorias distintas. Pode-se dizer que os resultados desta análise de reprodução de modelos-padrão de Lei de PDM, identificados entre os municípios com nove ocorrências do radical "paisag", ilustram uma situação que se repete, com maior e menor grau de intensidade, nas demais faixas de ocorrências da referida unidade de registro. 
TABELA I | Repetiçóes de padrão de ocorrências do radical "paisag” nas Leis de PDM na faixa de municípios com nove ocorrências (35 municípios no Paraná)

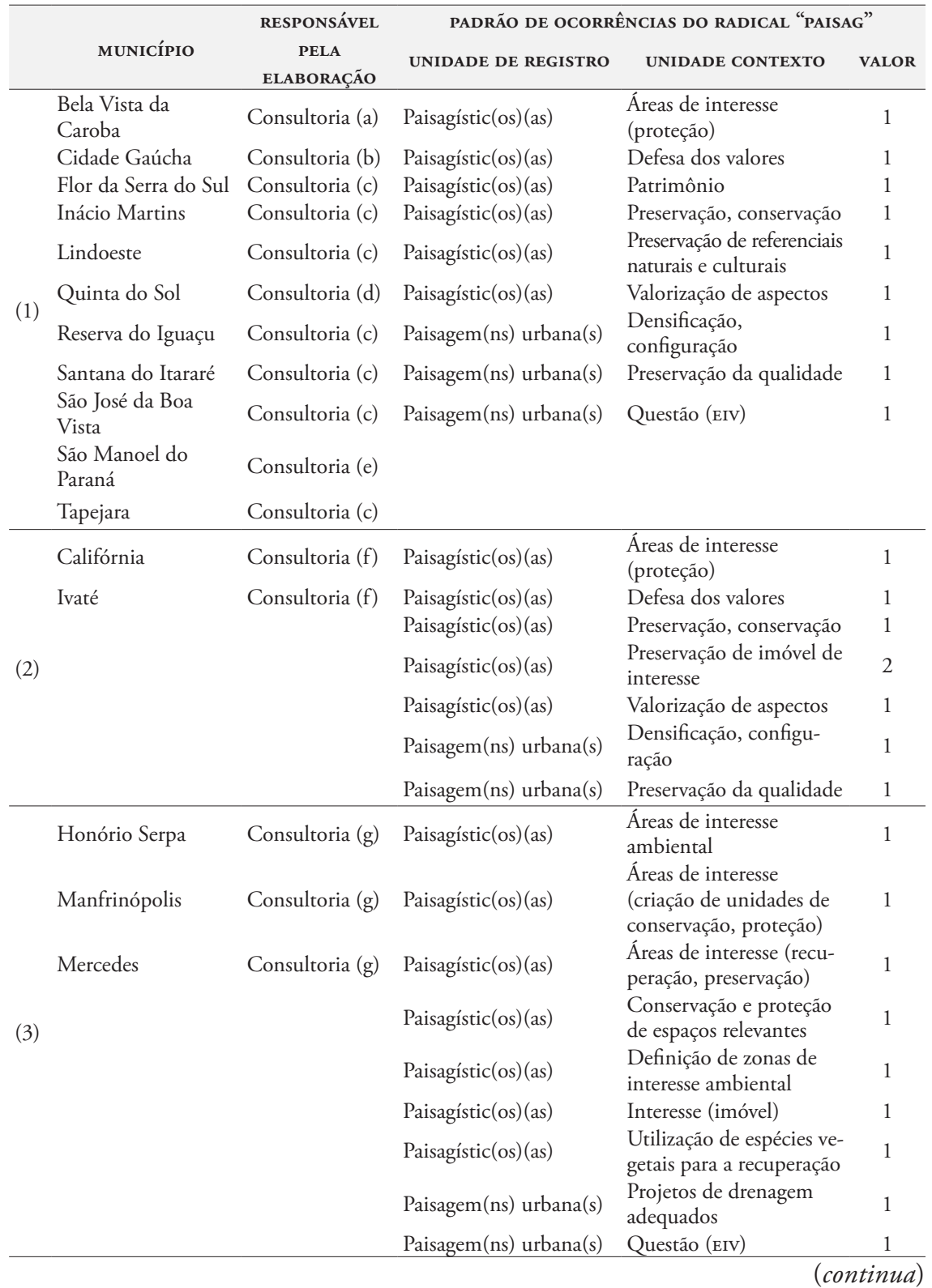


(continuação)

\begin{tabular}{|c|c|c|c|c|c|}
\hline \multirow{2}{*}{\multicolumn{2}{|c|}{ MUNICíPIO }} & \multirow{2}{*}{$\begin{array}{l}\text { RESPONSÁVEL } \\
\text { PELA } \\
\text { ELABORAÇÃo }\end{array}$} & \multicolumn{3}{|c|}{ PADRÁO DE OCORRÊNCIAS DO RADICAL "PAISAG" } \\
\hline & & & UNIDADE DE REGISTRO & UNIDADE CONTEXTO & VALOR \\
\hline \multirow{8}{*}{$(4)$} & Cruzeiro do Oeste & Consultoria (h) & Paisagístic(os)(as) & Áreas de notável valor & 1 \\
\hline & Tapira & Consultoria (i) & Paisagístic(os)(as) & Patrimônio & 2 \\
\hline & & & Paisagístic(os)(as) & Proteção e revitalização & 1 \\
\hline & & & Paisagístic(os)(as) & $\begin{array}{l}\text { Tombamento de bens } \\
\text { públicos ou privados de } \\
\text { caráter }\end{array}$ & 1 \\
\hline & & & Paisagístic(os)(as) & Valorização & 1 \\
\hline & & & Paisagem(ns) & Preservação & 1 \\
\hline & & & Paisagem(ns) urbana(s) & Evitar danos & 1,5 \\
\hline & & & Paisagem(ns) rural(is) & Evitar danos & 0,5 \\
\hline \multirow{9}{*}{$(5)$} & Santa Isabel do Ivaí & Consultoria (j) & Paisagístic(os)(as) & Áreas de interesse & 1 \\
\hline & São Carlos do Ivaí & Consultoria (j) & Paisagístic(os)(as) & Garantia qualidade & 1 \\
\hline & & & Paisagístic(os)(as) & $\begin{array}{l}\text { Interesse (manutenção } \\
\text { de imóveis, fachadas e } \\
\text { outros elementos arqui- } \\
\text { tetônicos ou naturais) }\end{array}$ & 1 \\
\hline & & & Paisagístic(os)(as) & Patrimônio & 2 \\
\hline & & & Paisagístic(os)(as) & $\begin{array}{l}\text { Proteção, revitalização } \\
\text { de bens de inequívoco } \\
\text { interesse }\end{array}$ & 1 \\
\hline & & & Paisagem(ns) urbana(s) & Baixa qualidade & 1 \\
\hline & & & Paisagem(ns) urbana(s) & $\begin{array}{l}\text { Boa qualidade (macrozo- } \\
\text { na urbana de consoli- } \\
\text { daçáo) }\end{array}$ & 1 \\
\hline & & & Paisagem(ns) urbana(s) & $\begin{array}{l}\text { Risco de comprometi- } \\
\text { mento }\end{array}$ & 1 \\
\hline & & & Paisagístic(os)(as) & Áreas de interesse & 1 \\
\hline
\end{tabular}

FONTE CAETANO, 2017

\section{Análise das unidades de significado}

As maiores ocorrências do radical "paisag", conforme ilustrado na Tabela 2, correspondem à ideia de paisagem associada à categoria de "produção do território habitado” e se devem à reproduçấo de textos dos instrumentos da política de desenvolvimento urbano, previstos no EC, nas leis dos PDMs. Nesse âmbito, ao menos no plano teórico, a paisagem aparece nos PDMs ora como algo que possui valor material ou potencial econômico, como: "valorização das potencialidades paisagísticas", ora como algo pré-existente a qual as novas obras humanas devem se adequar, como "preservação da paisagem urbana”.

A segunda categoria que apresentou maior número de ocorrências está associada à ideia de paisagem como meio ambiente dinâmico. Nessa porta de leitura, a dimensão ambiental do PDM ganha força, com o entendimento de que o território municipal faz parte de um ecossistema que extrapola seus limites, ao qual as açóes do PDM devem estar integradas para garantir o equilíbrio entre a capacidade de suporte ambiental e as demandas de crescimento urbano, visando um desenvolvimento mais sustentável e um "funcionamento" mais adequado entre as açóes humanas e a natureza. Sob esta ótica, apareceram nos PDMs ocorrências como "patrimônio 
paisagístico", da mesma forma como foi previsto na CF e no EC, "função ambiental de preservar a paisagem" e "manutenção do equilíbrio paisagístico".

A categoria associada à ideia de paisagem como representação cultural aparece na terceira posição em número de ocorrências. Nessa categoria de análise está presente o valor simbólico e representativo da paisagem como um bem material e imaterial que marca e é marcada pela cultura local, e possui papel fundamental na formação da identidade coletiva e no estabelecimento de vínculos dos indivíduos entre si, e destes com o território. Nessa porta de leitura se destacam ocorrências como "defesa de valores paisagísticos", "leitura e compreensão da paisagem" e "valor estéticopaisagístico natural ou cultural”.

Em quarto, a paisagem como projeto, está associada às propostas de intervençôes físicas de "jardinagem" nos espaços públicos da cidade, como ruas, praças e parques, caracterizadas basicamente pelo plantio de vegetação herbácea, arbustiva ou arbórea para tornar menos "áridos" os espaços de uso comum da cidade e, consequentemente, "melhorar" a estética urbana. Nessa porta de leitura, o radical "paisag" apareceu, em muitos casos, nos PDMs do Paraná como "paisagismo", termo comumente utilizado para denominar ação humana de ajardinamento de um espaço qualquer visando tornar sua ambiência mais agradável ao usuário. Nesse entendimento se destacaram ocorrências como "tratamento paisagístico", "qualificação da paisagem urbana”, e "requalificação da paisagem".

Nesse esforço interpretativo, as ideias de paisagem associadas à categoria de experiência sensorial foram as menos encontradas, com números bem inferiores às demais. Talvez por ser a mais subjetiva das portas de leitura da paisagem, que demandaria do planejador maior pré-disposição para captar, de corpo presente, toda a complexidade e sutileza de situaçóes visíveis e invisíveis que dão sentido ao lugar objeto de estudo. Pode-se afirmar que essa categoria de análise tem sido nitidamente negligenciada nos PDMs do Paraná.

TABEla 2 Levantamento das unidades de significado - cinco portas de leitura da paisagem de Besse - no Paraná

\begin{tabular}{|c|c|c|c|c|c|}
\hline \multirow[b]{2}{*}{$\begin{array}{l}\text { UNIDADE DE } \\
\text { SIGNIFICADO }\end{array}$} & \multicolumn{2}{|c|}{ LEI DE PDM } & \multirow{2}{*}{$\begin{array}{l}\text { UNIDADE DE } \\
\text { SIGNIFICADO }\end{array}$} & \multicolumn{2}{|c|}{ LUOS } \\
\hline & $\begin{array}{l}\text { QUANTI- } \\
\text { DADE }\end{array}$ & $(\%)$ & & $\begin{array}{l}\text { QUANTI- } \\
\text { DADE }\end{array}$ & $(\%)$ \\
\hline $\begin{array}{l}\text { Produção do território } \\
\text { habitado }\end{array}$ & $1.436,0$ & 42,60 & $\begin{array}{l}\text { Produção do território } \\
\text { habitado }\end{array}$ & 286,0 & 28,71 \\
\hline Meio ambiente dinâmico & 954,5 & 28,32 & Meio ambiente dinâmico & 257,0 & 25,80 \\
\hline Representação cultural & 506,0 & 15,01 & Representação cultural & 226,0 & 22,69 \\
\hline Projeto & 419,5 & 12,44 & Projeto & 132,0 & 13,25 \\
\hline Experiência sensorial & 18,0 & 0,53 & Experiência sensorial & 9,0 & 0,90 \\
\hline Indefinido & 37,0 & 1,10 & Indefinido & 86,0 & 8,63 \\
\hline Total & $3.371,0$ & 100 & Total & 996,0 & 100 \\
\hline
\end{tabular}


Tal ausência pode ser explicada pelo processo tradicionalmente adotado de elaboração de um PDM, onde as questóes são, em geral, colocadas de forma macro, os prazos de execução são apertados e há necessidade de priorização de açóes e investimentos em função da limitação de recursos. Isso faz com que, dificilmente se tome o devido cuidado com o lugar de intervenção, relevando seus mais ricos pormenores que o tornam singular. Mesmo com dificuldade, foram encontradas algumas ocorrências associadas à essa porta de leitura como: "fruição da paisagem", "inserção da arte pública na paisagem urbana", "desfrutar de belas paisagens naturais" e "observação da paisagem”.

\section{Consideraçóes finais}

Pode-se dizer que, de maneira geral, as Leis de PDM e Luos do Paraná trataram da questáo da paisagem de maneira superficial, limitando-se a reproduzir os cuidados que se deve tomar frente à mesma que já estão previstos em lei federal, especificamente no EC. Nesse sentido, os resultados encontrados induzem a afirmar que a paisagem não foi considerada como questão estruturante para a legislação dos PDMs do Paraná. Pode-se dizer que a paisagem, assim como outras questóes afetas à legislação urbanística, tende a sofrer com a falta de operacionalização de propostas previstas na Lei de PDM que, de tão genéricas, dificilmente conseguem transpor o campo da "boa intenção".

Da mesma forma como o radical "paisag" aparece no EC, em grande medida, ele tendeu a aparecer nas Leis de PDM e Luos do Paraná. No caso da paisagem, e imagina-se que isso também ocorra em outras questóes tratadas no PDM, a simples reprodução, em leis urbanísticas municipais, de princípios e objetivos já previstos em instrumentos jurídicos de âmbito federal ou estadual, pouco ou nada contribuem para transpor as ideias e propostas presentes no "mundo legal" para o "mundo material".

Em relação às ideias de paisagem presentes nas Leis de PDMs e Luos do Paraná, os resultados da pesquisa mostraram que predominou numericamente a ideia de paisagem associada à categoria "território fabricado e habitado", tanto no conjunto das Leis de PDM quanto nas Luos. Reputam-se como determinantes para a predominância deste resultado, em relação às demais portas de leitura, a combinação de dois fatores: i) a reprodução das disposiçôes gerais dos instrumentos da política de desenvolvimento urbano que já são previstos no EC; e ii) a reprodução de modelospadrão de Leis de PDM e Luos em municípios distintos.

Tal situação fez transparecer a percepção de que, as ideias de paisagem presentes nas Leis de PDM e Luos do Paraná representam muito mais um mosaico de modelosprontos de legislação urbanística disseminadas pelo Estado do que um mosaico da diversidade das paisagens paranaenses, que corresponderia à representaçáo de aspectos físicos e culturais que diferenciam o Paraná dos demais estados do Brasil.

Os três PDMs que apresentaram maior ocorrência do radical "paisag" nas Leis de PDM do Paraná foram elaborados por equipe própria do município. Já os PDMs que apresentaram as duas maiores ocorrências do mesmo radical nas LUOS, um deles foi elaborado por consultoria (Paranaguá) e o outro elaborado por equipe própria 
(Pato Branco). Os resultados da pesquisa indicaram que, em geral, PDMs elaborados por equipe própria tendem a trazer mais referências locais sobre a paisagem na legislação urbanística do que em PDMs elaborados por consultorias, que tendem a utilizar modelos-padrão de legislaçáo. Não se pode afirmar, todavia, que nos casos de elaboração de PDM por equipe própria não aconteça a utilização de modelospadrâo de legislação, porém, estima-se que a tendência de isso acontecer seja menor neste caso do que nos casos de PDMs elaborados por consultoria.

A pesquisa ora apresentada possui o mérito de ser extensiva a um recorte territorial preciso -o Estado do Paraná- e instigante no cenário nacional, uma vez que a legislação estadual forçou uma circunstância inédita no país, pois a grande maioria dos municípios paranaenses (95\%) possuem PDM. Dessa forma, constitui-se em caso relevante de estudo, que instiga a reflexão sobre o tratamento da paisagem no bojo legal dos PDMs produzidos desde o marco legal do EC. Sua maior potencialidade, para além de expor essa situação, advém de sua abordagem metodológica, que pode ser replicada por estudos em outros contextos. Contudo, dado o viés quantitativo, as minúcias dessa construção legal não puderam ser aferidas, fato que aponta para possível agenda de pesquisa futura. Outra abordagem que pode se revelar instigante para trabalhos posteriores atém-se à compreensão da importância de termos correlatos ao conceito da paisagem dentro dos corpos legais avaliados.

Por fim, se, por um lado, é necessário reconhecer que apenas a adequação dos instrumentos jurídico-urbanísticos vigentes não é suficiente para contemplar as questóes afetas à paisagem em sua plenitude, considerando os embates epistemológicos existentes na academia e a falta de consenso quanto a este tema, por outro, fica claro que, ao menos no Paraná, os seus PDMs, especialmente as suas legislaçóes urbanísticas, ainda têm muito que avançar qualitativamente para serem, de fato, reconhecidos como representativos do que foram, sáo e ainda poderáo ser as paisagens paranaenses.

\section{Referências bibliograficas}

Ab'Sáber, A. (2003). Os dominios de natureza no Brasil: potencialidades paisagisticas (7a ed.). São Paulo: Ateliê Editorial.

Andreotti, G. (2012). O senso ético e estético da paisagem. RA'E GA, 24, 05-17. https://doi. org/10.5380/raega.v24ii0.26191

Bardin, L. (2002). Análise de conteúdo. Lisboa: Ediçóes 70.

Barros, P. M. \& Pádua, L. (2014). As noçóes acerca da paisagem para a geografia: o percurso para o fundamento fenomenológico. Anais do $3^{\circ}$ Colóquio Ibero-Americano Paisagem Cultural, Patrimônio e Projeto, Belo Horizonte, MG, Brasil. Em http://www. forumpatrimonio.com.br/paisagem2014/artigos/pdf/77.pdf

Bertrand, G. (2004). Paisagem e geografia física global: esboço metodológico. RA'E GA, 8, 141152. https://doi.org/10.5380/raega.v8i0

Besse, J. M. (2014). O gosto do mundo: exercícios de paisagem. Rio de Janeiro, RJ: Eduerj. 
Caetano, F. D. (2017). As ideias de paisagem nos planos diretores municipais do Estado do Paraná. Dissertação de Mestrado, Programa de Pós-graduação em Geografia/Universidade Federal do Paraná, Curitiba. Em http://hdl.handle.net/1884/49402

Cancela d'Abreu, A., Botelho, M. J., Oliveira, M. R. \& Afonso, M. (2011). A paisagem na revisão dos PDM: orientaçóes para a implementação da Convenção Europeia da Paisagem no âmbito municipal. Lisboa: Direção Geral do Ordenamento do Território e Desenvolvimento Urbano (DGOTDU). Em https://bit.ly/2EGgrK7

Collot, M. (2012). Pontos de vista sobre a percepção de paisagens. Em: C. Negreiros, I. Alves \& M. Lemos (Orgs.). Literatura e paisagem em diálogo (pp. 11-28). Rio de Janeiro, RJ: Ediçôes Makunaima. Em http://edicoesmakunaima.com.br/images/livros/literatura_ epaisagem.pdf

Cosgrove, D. (1998). A geografia está em toda parte: cultura e simbolismo nas paisagens humanas. Em: R. L. Corrêa \& Z. Rosendahl (Orgs.). Paisagem, tempo e cultura (pp.92123). Rio de Janeiro, RJ: Eduerj.

Cosgrove, D. (2002). Observando la naturaleza: el paisaje y el sentido europeo de la vista. Boletín de la A.G.E, (34), 63-89. Em https://dialnet.unirioja.es/descarga/articulo/660033.pdf

Cosgrove, D. \& Jackson, P. (1987). New Directions in Cultural Geography. Area, 19(2), 95101. Em http://www.jstor.org/stable/20002425

Custódio, M. M. (2014). Introdução ao direito de paisagem: contribuição ao seu reconhecimento como ciência no Brasil. Rio de Janeiro, RJ: Lumem Juris.

Dardel, E. (2013). O Homem e a Terra: natureza da realidade geográfica. Em V. Bartalini (org.), Paisagem Textos 1 (pp. 81-145). São Paulo, sp: Faculdade de Arquitetura e Urbanismo, Universidade de São Paulo (Fau-Usp).

Dearden, P. (1984). Factors influencing landscape preferences: an empirical investigation. Landscape Planning, 11(4), 293-306. https://doi.org/1016/0304-3924(84)90026-1

Forman, R. T. T. (1996). Land mosaics: the ecology of landscapes and regions. Cambridge, uK: Cambridge University Press.

Harvey, D. (2002, julho). Mundos urbanos possíveis. Novos Estudos, (63), 3-8. Em http:// novosestudos.uol.com.br/produto/edicao-63/\#591a7c0250895

Jackson, J. B. (1984). The word itself. Em J. B. Jackson, Discovering the vernacular landscape (pp. 3-8). New Haven, ст: Yale University Press. Em https://digitalmedia.arts.ufl. edu/ -jack/home/images/9/9f/Jackson,JB_Vernacular_Landscape.pdf

Jacques, P. B. (2008, fevereiro). Corpografias urbanas. Arquitextos. Em http://www.vitruvius. com.br/revistas/read/arquitextos/08.093/165

Lynch, K. (1975).¿De qué tiempo es este lugar? Barcelona: GG.

McHarg, I. L. (1969). Design with nature. Nueva York: American Museum of Natural History. Palka, E. (1995). Coming to grips with the concept of landscape. Landscape Journal, 14(1), 63-73. https://doi.org/10.3368/lj.14.1.63

Pereira, G. (2010). Planos diretores no Paraná: uma avaliação qualitativa. Revista Paranaense de Desenvolvimento, (119), 113-135. Em http://www.ipardes.pr.gov.br/ojs/index.php/ revistaparanaense/article/view/247

Ribeiro, R. W. (2007). Paisagem cultural e patrimônio. Rio de Janeiro, RJ: Iphan/Copedoc. Em http://portal.iphan.gov.br/uploads/publicacao/SerPesDoc1_PaisagemCultural_m.pdf

Sandeville, E., Jr. (2005). Paisagem. Paisagem e Ambiente, (20), 01-10. https://doi.org/10.11606/ issn.2359-5361.v0i20p47-59 
Santos, E. A. (2003, junho). Por que planejar com a paisagem. Pós - Revista do programa de PósGraduação em Arquitetura e Urbanismo da fausp, 100-123. https://doi.org/10.11606/ issn.2317-2762.v13i0p100-123

Santos,M.(2002).Otemponascidades. Ciênciae Cultura, 54(2), 21-22.Emhttp://cienciaecultura. bvs.br/scielo.php?script=sci_arttext\&pid=S0009-67252002000200020

Schama, S. (1996). Paisagem e memória. São Paulo, sp: Companhia das Letras.

Simmel, G. (1913/2013). A filosofia da paisagem. Em V. Bartalini (org.), Paisagem Textos 1 (pp. 19-27). São Paulo, sp: Fau-Usp.

Troll, C. (1997). A paisagem geográfica e sua investigação. Espaço e Cultura, 4, 1-7. https://doi. org/10.12957/espacoecultura.1997.6770

Tuan, Y. (1980). Topofilia: um estudo da percep̧ção, atitudes e valores do meio ambiente. São Paulo, SP: Difel.

Veiga, J. E. (2005). O prelúdio do desenvolvimento sustentável. Em https://edisciplinas.usp.br/ pluginfile.php $/ 2514681 / \mathrm{mod} \_r e s o u r c e / c o n t e n t / 2 / T e x t o \% 20 \_\% 20$ desenvolvimento_ sustentavel.pdf

Veiga, J. E. (2006, janeiro/março). Territórios para um desenvolvimento sustentável. Ciência e Cultura, 20-24. Em http://cienciaecultura.bvs.br/pdf/cic/v58n1/a12v58n1.pdf

Villaça, F. (1999a). Dilemas do plano piretor. In: Fundação Prefeito Faria Lima - Cepam. $O$ Município no Século XXI (pp. 237-248). São Paulo, sp: Cepam \& Correios. Em http:// www.uff.br/pur/files/2011/04/Dilemas_PD_Villa\%C3\%A7a1.pdf

Villaça, F. (1999b). Uma contribuição para a história do planejamento urbano no Brasil. Em C. Deák \& S. T. R. Schiffer (orgs.), O processo de urbanização no Brasil (pp. 169-244). São Paulo, sp: Edusp.

Villaça, F. (2005). As ilusōes do plano diretor. São Paulo: Edição do autor. 